\title{
GAMEBOOK E A ESTIMULAÇÃO DE FUNÇÕES EXECUTIVAS EM CRIANÇAS COM INDICAÇÃO DE DIAGNÓSTICO DE TDAH: PROCESSO DE PRÉ- PRODUÇÃO, PRODUÇÃO E AVALIAÇÃO DO SOFTWARE
}

Lynn Alves*

Camila Bonfim**

\begin{abstract}
RESUMO
Este artigo objetiva descrever o processo de desenvolvimento do Gamebook, uma mídia híbrida com características de jogo digital e appbook, desenvolvido para estimular as Funções Executivas (FE) de crianças na faixa etária de 8 a 12 anos especialmente com diagnóstico de Transtorno de Déficit de Atenção e Hiperatividade (TDAH). A metodologia foi de base qualitativa, dialogando com a perspectiva multirreferencial, exploratória e descritiva, com prática colaborativa mediada com os distintos saberes nas reuniões entre os membros da equipe e pesquisadores/especialistas parceiros. Para identificar o perfil das crianças que interagem com a cultura digital e apresentam diagnóstico de TDAH utilizamos questionário on-line, respondido com a mediação de pais e especialistas. Isso subsidiou o desenvolvimento, avaliação e retroalimentação do gamebook, concretizando-se em ambiente interativo com 8 minigames. O gamebook encontra-se disponível, gratuitamente, nas Appstores para tablet nos sistemas operacionais IOS e Android. O projeto encontra-se agora na fase de investigação com crianças com diagnóstico de TDAH, para avaliar a contribuição dos minigames ao estimular as FE. Assim, o artigo aqui proposto apresenta os resultados da primeira fase da investigação, que a partir da avaliação dos especialistas conclui que os ambientes interativos, como o gamebook, podem se constituir em lócus de aprendizagem e estimulação das FE.
\end{abstract}

Palavras-chave: Gamebook. Funções executivas. TDAH.

\section{ABSTRACT \\ GAMEBOOK AND STIMULATING EXECUTIVE FUNCTIONS IN CHILDREN WITH DIAGNOSED ADHD TENDENCIES: PRE-PRODUCTION PROCESS, PRODUCTION AND SOFTWARE EVALUATION \\ This article describes the development process of Gamebook, a hybrid media with}

\footnotetext{
* Pós-doutorado em Jogos Digitais e Aprendizagem pela Universidade de Turim. Doutorado em Educação pela Faculdade de Educação da Universidade Federal da Bahia (FACED/UFBA). Professora Titular da Universidade do Estado da Bahia (UNEB) e da Faculdade SENAI CIMATEC. Integrante do Grupo de Pesquisa Comunidades Virtuais (UNEB). E-mail: lynnalves@, gmail.com

** Mestrado em Saúde Coletiva pelo Instituto de Saúde Coletiva da Universidade Federal da Bahia (ISC/UFBA). Professora Assistente nível A da Universidade do Estado da Bahia (UNEB) e da Faculdade Ruy Barbosa. Integrante do Grupo de Pesquisa Comunidades Virtuais (UNEB). E-mail: bonfimcamila@yahoo.com.br
} 
features of digital games and AppBook which was designed to stimulate the Executive Functions (EF) of children between 8 and 12 years, especially those with a diagnosis of Attention Deficit Hyperactivity Disorder (ADHD). The methodological approach used was qualitative with a multi-referential, exploratory and descriptive perspectives and a collaborative approach with distinct knowledge through meetings between team members and researchers/experts. An online questionnaire was used to identify the profile of children who interact with the digital culture and have diagnosed ADHD and parents and experts helped children to fill in it. This process supported the development, evaluation and feedback of Gamebook with 8 minigames that stimulate EF. The gamebook is freely available for tablets in AppStores in IOS and Android operational systems. The project is now in the research phase with children diagnosed with ADHD and the aim is to assess the contribution of minigames to stimulate EF. This article presents the results of the first phase of the research from the evaluation of experts. We conclude that interactive environments such as Gamebook might be a good learning locus and stimulator for EF.

Keywords: Gamebook. Executive functions. ADHD.

\section{RESUMEN}

\section{GAMEBOOK Y ESTIMULACIÓN DE LAS FUNCIONES EJECUTIVAS EN NIÑOS CON INDICACIÓN DE DIAGNÓSTICO DE TDAH: PRE-PRODUCCIÓN, PRODUCCIÓN Y EVALUACIÓN DEL SOFTWARE}

Este articulo tiene como objetivo describir el proceso de desarrollo de un Gamebook, como un medio de comunicación híbrido mediante el uso de juegos digitales y AppBook desarrollados para estimular las funciones ejecutivas (FE) en niños de 8 a 12 años, con diagnóstico de trastorno por déficit de atención e hiperactividad (TDAH). La metodología de base fue: cualitativa, dialogando con la perspectiva multi-referencial, exploratoria y descriptiva con la colaboración $\mathrm{y}$ aporte de distintos saberes de miembros del equipo y de investigadores/ expertos asociados. Para identificar el perfil de los niños que interactúan con la cultura digital y presentan diagnóstico de TDAH se utilizo un cuestionario online resuelto con la intervención de los padres y especialistas. Información que fue usada para el desarrollo, evaluación y retroalimentación de gamebook, dando como resultado 8 mini juegos. El Gamebook está disponible en AppStores para IOS y Android sin costo. El proyecto se encuentra ahora en la fase en la que se evaluará la contribución de mini juegos en la estimulación de las FE en niños con TDAH. Así, este artículo presenta los resultados de la primera fase de evaluación que a partir de la evaluación de los especialistas llega a la conclusión de que, los entornos interactivos como el Gamebook pueden constituir con el aprendizaje y estimulación de las FE.

Palabras clave: Gamebook. Funciones ejecutivas. TDAH. 


\section{Introdução}

A discussão sobre os jogos digitais e a aprendizagem vem crescendo de forma significativa no cenário acadêmico. Em uma investigação realizada pelo Centro de Pesquisa e Desenvolvimento Comunidades Virtuais (CPDCV) e coordenada por Alves (2013), no período de 2010 a 2012, foi possível constatar que uma das áreas que mais produziu conhecimento sobre os jogos digitais no Brasil foi a área de educação. No período de 1994 a 2010, foram produzidas 93 dissertações e 18 teses. Contudo, esse crescimento não reflete em práticas pedagógicas mediadas pelos jogos digitais. No Brasil, podemos destacar de forma mais efetiva o trabalho desenvolvido pela Empresa Joy Street em parceria com as secretarias de educação dos estados de Pernambuco, Acre, Sergipe e Rio de Janeiro, que, anualmente, realizam as Olimpíadas dos Jogos Eletrônicos (JOY STREET, 2016), tensionando a dinâmica escolar na rede pública.

Experiências pontuais que vêm sendo desenvolvidas por algumas escolas privadas com a mediação do game Minecraft, também ganham espaço nos cenários pedagógicos e especialmente na mídia (INSTITUTO CLARO, 2013; MINECRAFT..., 2015; YAMAMOTO, 2015). O trabalho do CPDCV também tem contribuído para a discussão e ações mediadas pelos jogos digitais. Ao longo dos últimos quatorze anos, este grupo produziu onze jogos e em 2015 concluiu o desenvolvimento do Gamebook, uma mídia híbrida com elementos de games e appbooks, disponível nas lojas das Appstores da Google Play e Apple Store gratuitamente, apenas para tablet. O appbook se caracteriza por foco na experiência do usuário, podendo ou não ter como referência uma narrativa originalmente advinda do livro impresso (Tal qual os aplicativos de leitura, os appbooks também podem fazer uso de estratégias de simulação da brochura) e por serem frequentemente utilizados como canais alternativos para narrativas transmídia.

O Gamebook Guardiões da Floresta (GGF) (COMUNIDADES VIRTUAIS, 2016), nesta primeira fase foi financiado pela CAPES, FAPESB, CNPq e UNEB. Sintonizada com a perspectiva transmidiática, na qual uma narrativa pode ser distribuída em distintas linguagens, o GGF amplia a narrativa iniciada no jogo digital Guardiões da Floresta (COMUNIDADES VIRTUAIS, 2013), criando uma nova linguagem midiática, neste caso um gamebook, para estimular as Funções Executivas (FE), especialmente para crianças na faixa etária de 8 a 12 anos com indicação de Transtorno de Déficit de Atenção e Hiperatividade (TDAH).

É dentro desse contexto que se insere este artigo, que tem o objetivo de apresentar os resultados da fase inicial de avaliação do Gamebook realizado por um grupo de três juízes formado por pesquisadores e especialistas que atuam na área de neuropsicologia na cidade de Salvador, atendendo crianças com indicação de diagnóstico de TDAH. Os resultados dessa avaliação subsidiaram o processo de produção da mídia, balanceando os minigames existentes no GGF a fim de estimular as funções executivas definidas anteriormente pela equipe de desenvolvedores.

\section{Funções executivas e jogos digitais}

As funções executivas constituem-se em um conceito guarda-chuva que engloba diversos processos cognitivos (MALLOY-DINIZ et al, 2010). Estas funções envolvem habilidades como a memória de trabalho, planejamento, flexibilidade cognitiva, categorização, controle inibitório e atenção sustentada (CAPOVILLA; ASSEF; COZZA, 2007). São consideradas funções metacognitivas, pois mais do que cognitivas, estas funções não se referem apenas a uma habilidade mental específica, mas oferecem organização abrangente para todas elas. Por isso são chamadas de funções executivas, pela analogia à função de um grande executivo de uma empresa, ou o maestro de uma orquestra (GOLDBERG, 2002). Seu processamento ocorre nas chamadas áreas pré-frontais, zonas extremamente conectadas com outras regiões do cérebro e por isso ocupa papel importante na integração de diferentes funções cognitivas (GOLDBERG, 2002).

Por apresentar um papel tão central na organização cerebral, o comprometimento dessas funções 
gera diversos impactos na vida social, organização de vida diária e controle emocional (MALLOY-DINIZ et al., 2010). Diversas patologias cognitivas estão associadas a disfunções executivas, especialmente o TDAH. O TDAH consiste em um transtorno do neurodesenvolvimento marcado por níveis prejudiciais de desatenção, desorganização e/ou hiperatividade-impulsividade (AMERICAN PSYCHIATRIC ASSOCIATION, 2015). Esse comprometimento é persistente por pelo menos seis meses e deve trazer prejuízos substanciais a atividades sociais, acadêmicas ou profissionais, sendo geralmente diagnosticado a partir dos seis anos. As causas do transtorno ainda estão sendo investigadas, mas fatores de riscos neurobiológicos, pré-natais, perinatais, ambientais, alimentícios e genéticos têm sido os mais investigados (AMERICAN PSYCHIATRIC ASSOCIATION, 2015). Estima-se que a prevalência do TDAH varie entre $3 \%$ e $5 \%$ entre crianças, no entanto este transtorno tem sido diagnosticado em excesso, sendo também responsável pelo aumento da medicalização da infância, o que aponta para uma necessidade de maior investigação de sua manifestação (ASSOCIAÇÃO BRASILEIRA DO DÉFICIT DE ATENÇÃO, 2016).

A disfunção executiva é uma característica essencial do TDAH. Costuma se apresentar por meio de incapacidade de inibir a ação, dificuldades no planejamento e na capacidade de autorregulação da ação, incapacidade de direcionar o foco da atenção, de apresentar flexibilidade na alteração de estratégias em razão de novas contingências, bem como dificuldades de utilizar estratégias no armazenamento de informações (CAPOVILLA; ASSEF; COZZA, 2007). Essas alterações podem trazer prejuízos secundários à aprendizagem, especialmente problemas de leitura, escrita e/ou cálculo, portanto, há extenso comprometimento no desenvolvimento de diversas estruturas cerebrais responsáveis pelo processamento de funções complexas (ASSOCIAÇÃO BRASILEIRA DO DÉFICIT DE ATENÇÃO, 2016). Considerando que o TDAH tem sido um dos problemas de desenvolvimento neuropsicológico que mais traz impactos nos processos de aprendizagem (AMERICAN PSYCHIATRIC
ASSOCIATION, 2015), especialmente para crianças na faixa etária de 8 a 12 anos, é que o Gamebook surge como ambiente para mediação pedagógica e clínica.

Em uma pesquisa realizada no dia 2 de setembro de 2015, na Thompson Reuters, consultando as bases de dados Web of Science, Conference Proceedings e Current Contents Connect, com os descritores: funções executivas (executive functions), Transtorno de Déficit de Atenção e Hiperatividade (Attention Deficit Hyperactivity Disorder - ADHD) e jogos digitais (digital games), sem delimitar o período, encontramos apenas um trabalho, publicado em 2014, denominado Empowering Children With ADHD Learning Disabilities With the Kinems Kinect Learning Games, que se refere a um estudo realizado com 11 crianças na faixa etária de 4 a 8 anos com Transtorno de Déficit de Atenção e Hiperatividade, no hospital universitário de Atenas, na Grécia, com a mediação do Kinect. Os resultados do estudo indicaram que as crianças apresentaram uma melhora nas suas funções executivas e habilidades cognitivas após a realização do estudo, bem como interesse e motivação em participar da pesquisa (RETALIS et al, 2014).

Ao utilizarmos os descritores funções executivas (executive functions) e jogos digitais (digital games) encontramos apenas dois trabalhos. Um deles já indicado acima e o outro de autoria de Boyle e Boyle (2014), que propõem analisar os ganhos cognitivos para as funções executivas com a mediação dos jogos. Os autores realizam uma revisão sistemática partindo do modelo de memória de trabalho de Baddeley (BADDELEY; ANDERSEN; EYSENCK, 2011) e dois modelos de funções executivas, a de Anderson (2002) e a de Diamond (2013). No que se refere aos jogos digitais, Boyle e Boyle (2014) tomam como referência artigos que discutem a mediação dos games de forma mais ampla, já que não existem artigos que apresentem resultados das pesquisas que vêm investigando diretamente a relação entre jogos digitais e funções executivas.

Contudo, é importante destacar as investigações que vêm sendo desenvolvidas na Universidade da Califórnia, em São Francisco, sob a coordenação do Dr. Gazzaley e do grupo Akili, e 
divulgadas na mídia digital. O grupo Akili, formado por pesquisadores da área de neurociência e gamedesigners, com financiamento e parceria da Pfizer, Shire (indústrias farmacêuticas), National Institute of Mental Health e Autism Speaks, vem desenvolvendo o Project: Evo (AKILI INTERACTIVE, 2015).

O Dr. Gazzaley é diretor fundador do Imaging Center Neurociência da Universidade da Califórnia, San Francisco, Professor Associado de Neurologia, Fisiologia e Psiquiatria e investigador principal de um laboratório de neurociência cognitiva.

O Project Evo consiste em uma plataforma interativa, "gamificada" com três jogos denominados de clínicos que objetiva melhorar a atenção e memória de trabalho, dentre outras funções cognitivas de uma variada população que inclui crianças e idosos. As mecânicas dos jogos foram planejadas com o objetivo de aperfeiçoar as funções executivas como resolução de problemas, memória de trabalho e autorregulação (AKILI INTERACTIVE, 2015; ANDERSON, 2015; INNOVATION EXCELLENCE, 2015; JUNQUEIRA, 2016; PAI, 2015).

O grupo do professor Gazzaley já vem realizando investigações com a mediação do jogo Neuro-racer (um dos jogos da plataforma EVO) para melhorar as habilidades cognitivas que declinam com a idade em idosos, apresentando resultados significativos (ANGUERA et al., 2013).

Com um grupo de crianças, destaca-se o trabalho do pesquisador Scott Kollins, Professor de Psiquiatria e diretor do programa de Transtorno de Déficit de Atenção e Hiperatividade da Escola de Medicina da Universidade de Duke nos Estados Unidos que liderou um projeto piloto com a plataforma Evo, que envolveu pesquisadores do Centro de Pesquisa Clínica da Flórida e Suny Upstate Medical University de New York, que testou 80 crianças entre as idades de 8 e 12 anos, 40 dos quais foram diagnosticados com TDAH e que não tomava medicação e 40 dos quais não tinham diagnóstico psiquiátrico (ANDERSON, 2015; INNOVATION EXCELLENCE, 2015; PAI, 2015). ${ }^{1}$

1 Em correspondência por e-mail do dia 14 de fevereiro de 2016, o Dr. Kollins informou que os dados descritos acima foram parte de uma apresentação no American Academy of Child and Adolescent Psychiatry's 62nd annual meeting, realizado em 26 a 31 de outubro de 2015, na cidade de Santo Antônio - México. O pesquisador in-
Os sujeitos da pesquisa recebiam uma tablet com o jogo e durante o período de quatro semanas, trinta minutos por dia, sete dias por semana, interagiam em casa com a plataforma. Segundo os pesquisadores

Os objetivos primários do estudo foram para confirmar a viabilidade e segurança da intervenção em casa, bem como para medir a diferença no funcionamento da atenção de base entre os dois grupos. Medidas exploratórias de atenção, impulsividade e memória de trabalho também foram avaliadas em um mês. A melhora foi vista em todos estes domínios no grupo TDAH. (BUSINESS WIRE, 2015, tradução nossa)

O panorama acima nos aponta a emergência de novas perspectivas para a estimulação das funções executivas com a mediação de ambientes interativos, especialmente games, proporcionando, de forma lúdica, espaços alternativos de tratamento, diminuindo o uso abusivo de medicamentos para transtornos como TDAH.

Tais dados reforçam a importância de investigar a potencialidade dos jogos digitais para o desenvolvimento e treino das funções executivas. Portanto, dentro desse contexto, torna-se relevante a investigação que vem sendo realizada pelo CPDCV no que se refere à mediação do Gamebook para o desenvolvimento das funções executivas.

\section{Gamebook: do desenvolvimento da mídia para o processo de intervenção}

O Gamebook é um projeto financiado pela CAPES/FAPESB/CNPq e UNEB, e o processo de desenvolvimento da mídia envolveu uma equipe com distintas expertises tanto em nível de desenvolvimento quanto de pesquisa. O tempo de desenvolvimento foi de 20 meses, envolvendo três etapas: pré-produção, produção e avaliação.

Nesse projeto, adotamos uma perspectiva colaborativa com as crianças e especialistas a fim de discutir aspectos relacionados com o roteiro, a arte e a mecânica do GGF, sempre retroalimentando o processo a partir da contribuição de todos os atores envolvidos. Assim, as etapas de pré-produção, produção e avaliação foram

formou ainda que o manuscrito referente a esses dados encontra-se em preparação e provavelmente será publicado ainda em 2016. 
marcadas essencialmente por uma abordagem metodológica multirreferencial. Para Burnham (1993, p. 07), nesta abordagem:

O sujeito, porém, não se limita apenas às suas óticas e sistemas de referências particulares, uma vez que ele vive concomitante e duplamente num mundo interior (privado) e num mundo exterior a si mesmo (no caso do indivíduo social, mundo público), este último passando a fazer parte do sujeito através do permanente processo de socialização que permite a inserção deste mesmo sujeito, como parte dele [...] Em razão desta duplicidade de mundo em que vive o sujeito, Barbier informa que distingue a multirreferencialidade em interna e externa.

Logo, atentos aos distintos olhares, perspectivas, demandas e desejos dos sujeitos imersos no universo desta investigação, construímos coletivamente sentidos para o Gamebook, avaliando o potencial dos minigames para estimular as funções executivas dos sujeitos, retroalimentando o processo de desenvolvimento e, consequentemente, as intervenções junto às crianças.

Também utilizamos a abordagem metodológica exploratória e descritiva nas etapas de pré-produção, produção e avaliação. Segundo Gil (2008), a pesquisa exploratória tem como objetivo familiarizar-nos com um assunto pouco conhecido e explorado. Sendo assim, a pesquisa é exploratória, já que íamos construindo e delineando um sentido para o objeto de investigação, que ainda apresentava poucas referências de produções tanto em nível de jogos digitais, ambientes interativos, quanto reflexões teóricas sobre essas articulações descritas neste artigo. Já a pesquisa descritiva visa descrever características de uma população, objeto, fenômeno ou experiência (GIL, 2008). A pesquisa também é descritiva, pois realizamos a caracterização da população-alvo no processo de pré-produção, descrevemos as atividades de cada minigame no processo de produção e caracterizamos as funções executivas estimuladas em cada minigame do ponto de vista dos avaliadores na etapa da avaliação.

\section{A pré-produção}

Esta etapa consistiu em ações que subsidiaram o processo de desenvolvimento e são descritas a seguir. No período de outubro a dezembro de 2013, realizamos contatos com profissionais e pesquisadores das áreas de psicopedagogia, neuropsicologia, neurologia e psicologia que atendiam e/ou realizavam pesquisas com crianças que apresentavam sintomas de TDAH em Salvador. A partir destes contatos foi aplicado um questionário on-line (no Google docs) com o objetivo de identificar o perfil de sujeitos com diagnóstico e/ou indicação de TDAH e suas interações com o universo da cultura digital, especialmente os jogos digitais. O questionário foi disponibilizado através de listas de discussão, Facebook e nas clínicas parceiras do projeto neste primeiro momento.

Contamos com a participação de 55 sujeitos, sendo que 19 (34\%) responderam ao questionário presencialmente (isto é, o questionário foi entregue impresso) e 36 (66\%) virtualmente. A faixa etária dos participantes variou de 01 a 48 anos. $^{2}$

Ressaltamos que as crianças tiveram a mediação de um adulto (pais ou especialistas) para responder o questionário. Para atender aos objetivos da pesquisa, selecionamos apenas 21 sujeitos que estavam na faixa etária de 8 a 12 anos, que atendiam às características definidas para especificações do Gamebook. Tivemos 4 crianças com 8 anos; 1 com 9 anos; 9 com 10 anos; 6 com 11 anos; e 1 com 12 anos. A distribuição geográfica dos sujeitos teve predomínio em Salvador, com 18 respondentes, seguida por Petrolina, Recife e São Paulo, cada cidade com apenas um respondente.

No que se refere ao atendimento que realizava, 12 sujeitos informaram que estavam sendo atendidos numa clínica particular, uma das parceiras do projeto nessa primeira fase; 2 na clínica escola da UNEB; e 7 revelaram distintos locais de atendimento.

Quando investigados sobre o tipo de atendimento que recebiam, a maioria estava sendo acompanhado por profissionais de psicopedagogia e psicologia (Gráfico 1).

\footnotetext{
2 Acreditamos que o questionário do sujeito com a idade indicada de um ano foi preenchido pelo responsável e não fez parte do escopo da pesquisa entrar em contato direto com esses sujeitos, já que o objetivo do questionário era apenas delinear o perfil dos sujeitos com diagnóstico de TDAH.
} 
Gráfico 1 - Tipo de atendimento por sujeito

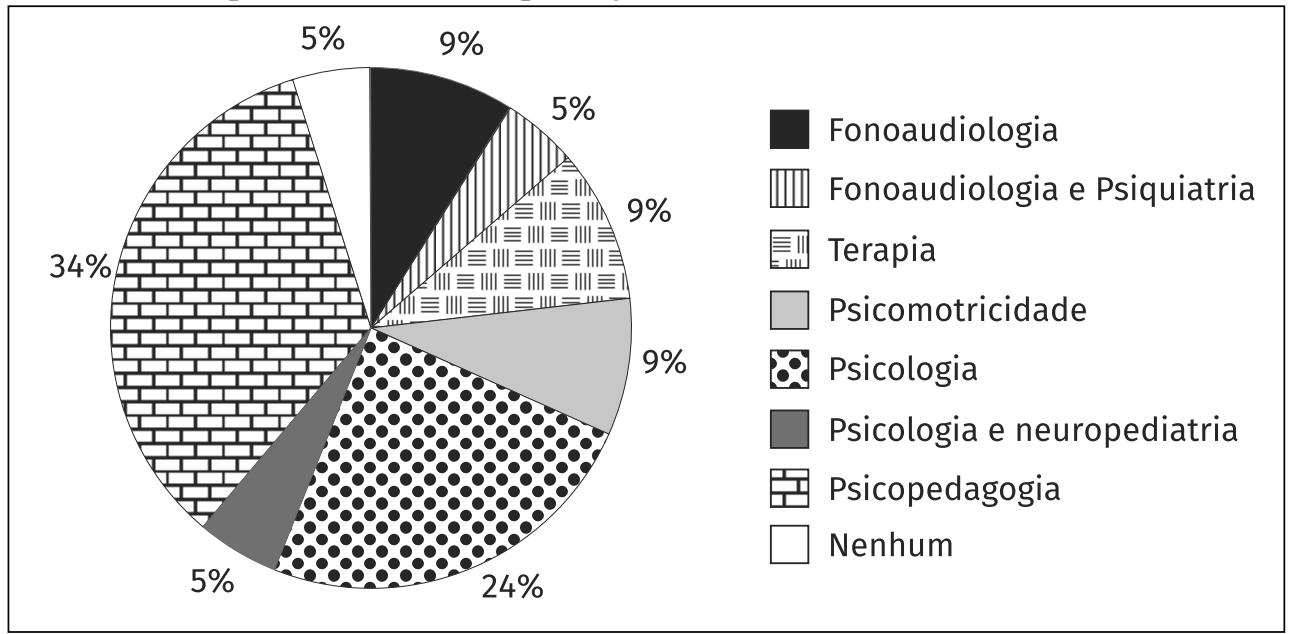

Fonte: Elaborado pelos autores deste artigo.

Quanto aos diagnósticos, 9 (43\%) indicaram ter algum dos seguintes diagnósticos: TDAH, coordenação motora lenta, paresia, audição unilateral, miopia, perda auditiva e transtorno opositor. Os demais (57\%) declararam não possuir nenhum diagnóstico definido. Não houve também indicação de comorbidade entre os participantes.

Os dados acima chamam nossa atenção, considerando que apesar de 57\% indicarem não ter nenhum diagnóstico definido, todos eles estão em atendimento com psicopedagogos ou psicólogos, o que pode indicar uma tendência a medicalizar os comportamentos infantis que fogem de algum tipo de padrão. Os dados apontam ainda que não foi encontrada defasagem idade/série. Quando questionados sobre a frequência com que interagiam com os jogos digitais, 15 sujeitos (71\%) indicaram que jogavam diariamente e $6(29 \%)$ jogavam de vez em quando. Sobre o tipo de plataforma de interação com jogos, verificou-se que o celular, especialmente os do tipo smartphone, vêm sendo a plataforma mais utilizada para acesso a conteúdos digitais (67\%), especialmente os games (GRAF.2). Contudo, considerando que as escolas públicas vêm recebendo tablets desde 2013, o projeto do Gamebook optou por desenvolver o ambiente com configurações de telas voltadas para esta plataforma.

Gráfico 2 - Frequência relativa do uso de plataformas de interação com os jogos

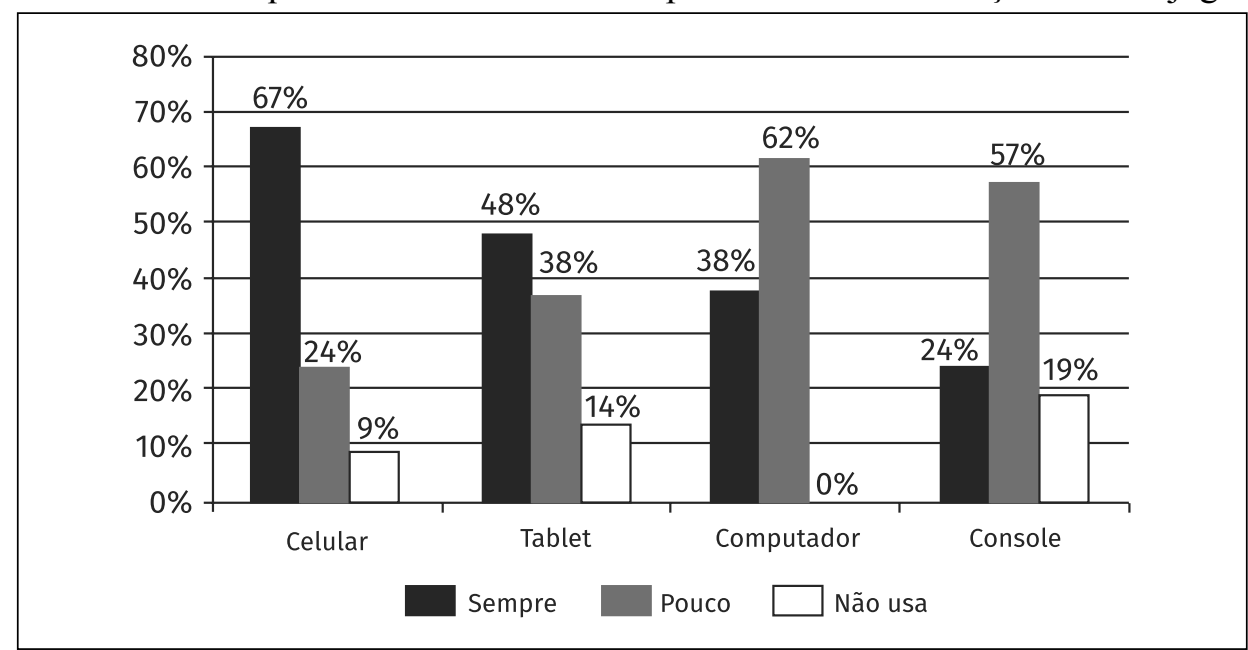

Fonte: Elaborado pelos autores deste artigo. 
No que se refere aos jogos que os sujeitos preferiam, os mais apreciados foram mundos abertos como o Minecraft, jogos de simulação, futebol e minimundos nos quais é possível interagir com outras pessoas. Vale destacar que dois sujeitos na faixa etária de 11 anos indicaram o Grand Theft Auto (GTA) V como jogo preferido. O GTA V tem um conteúdo considerado violento e apresenta situações de inversão de valores, sendo, inclusive, contraindicado para menores de 18 anos. Este dado é interessante, pois nos leva a questionar se os pais acompanham a interação das crianças com este tipo de jogo.

As imagens, os desafios e a história foram apontados por todos os sujeitos como os aspectos que mais chamavam atenção no universo dos jogos. Outro ponto interessante foi a preferência por jogos do tipo multiplayer (43\%) em contraponto aos do tipo singleplayer (38\%). Há ainda aqueles que preferem jogos os dois tipos (19\%). Estes dados apontam a necessidade de interação com o outro, de jogar com seus pares, de terem interlocutores.
As questões relacionadas com a prática da leitura também foram investigadas e os dados também subsidiaram o desenvolvimento do gamebook que se constitui em uma mídia híbrida com elementos de game e de appbook (narrativas interativas).

Os sujeitos registraram diferentes formas de interação com o conteúdo letrado, evidenciando que a História em Quadrinho ainda ocupa um lugar de destaque no universo da leitura (38\%), mas vale a pena destacar quatro registros diferenciados: um sujeito de 12 anos que lia jornal; um que compreendia o universo do jogo como espaço de leitura; outro que interagia com a leitura através do Facebook e por fim, um que apresentava uma concepção de leitura ainda bastante incipiente - ler as letras. Outro dado preocupante é que $23 \%$ dos sujeitos ainda estão distantes do prazer e do hábito de ler. Os dados ratificam a discussão já realizada por Santaella (2004) da emergência de um leitor movente, fragmentado, não mais contemplativo, mas que transita nos diferentes suportes rapidamente e com níveis de concentração mais baixos (Gráfico 3).

Gráfico 3 - Principais fontes de leitura

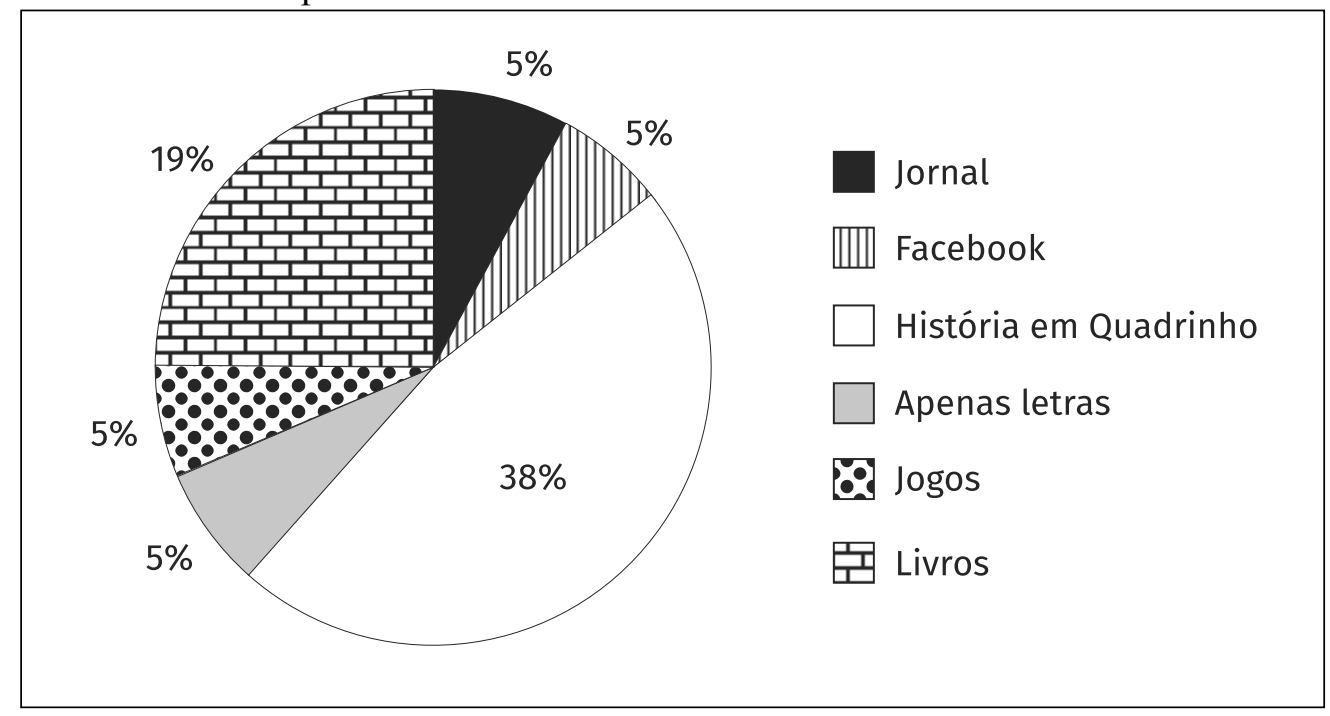

Fonte: Elaborado pelos autores deste artigo.

Dessa forma, os resultados da pesquisa da fase de pré-produção do Gamebook indicaram que o perfil dos sujeitos entrevistados era constituído por crianças que estavam sendo acompanhadas por profissionais da área de psicopedagogia ou psicologia, com diagnóstico indefinido e sem comorbidades, sem defasagem idade/série, jogadores diários, preferencialmente em smartphones, apreciadores de jogos do tipo mundos abertos e multiplayers e leitores de histórias em quadrinhos.

Ainda na fase de pré-produção, considerando os dados apresentados acima e o estudo de similares que foi desenvolvido pelo grupo, bem como as discussões teóricas, delineamos os elementos que 
iriam compor o roteiro do Gamebook. A princípio uma narrativa bifurcada, que depois de doze meses de produção sofreu mudanças por conta de questões relacionadas ao tempo e aos aspectos técnicos que tensionaram o processo de produção.

\section{Uma mídia que nasce de muitas mídias}

O processo de produção do GGF envolveu um estudo de similares que explorou uma diversidade de linguagens que incluiu a literatura, como o livro O jogo da Amarelinha, de Júlio Cortázar (2005); a produção cinematográfica, com o filme "Rio 2", que também se passa na Amazônia; e, especialmente, os jogos digitais produzidos atualmente para potencializar e treinar as funções executivas, como "Lumosity", "Peak", "HappyNeuron", "Pedro no acampamento", "As aventuras do Ouriço-cacheiro, entre outros. O game "PlantsvsZombies" também foi analisado, considerando que, para vencer as hordas de zumbis (objetivo principal do jogo), são necessários planejamento, atenção seletiva, controle inibitório e flexibilidade cognitiva, dentre outras funções executivas.

Fizemos uma imersão no universo dos jogos digitais, no cinema e na literatura na busca por mídias que tivessem a denominação de gamebook, entretanto não encontramos nada que se aproximasse daquilo que almejávamos. Ambientes como "PiccoliPirati", "Dark Forest", "iPoe", "Nancy Drew" foram explorados; contudo percebemos que se constituíam em livros animados, com pouco nível de jogabilidade. No Brasil, os projetos desenvolvidos pelo site Livro e Game (FUNDAÇÃO TELEFONICA, 2011) distanciam-se dos livros e se aproximam dos games, partindo de três romances da literatura brasileira, a exemplo de Dom Casmuro, Memórias de um Sargento de Milícias e o Cortiço.

Uma iniciativa bastante significativa, relacionada ao termo gamebook, é "Guardião da Imaginação", que envolve narrativa, ilustrações interativas e jogos. Após a análise dessas distintas linguagens, entrevistas com neuropsicológos, psicopedagogos e com crianças com indicação diagnóstica de TDAH, a equipe do CPDCV, através de reuniões com muitas discussões, partiu em busca da produção do que compreendemos ser um Gamebook.

Esse processo de pré-produção possibilitou a construção de uma trilha diferenciada no grupo de pesquisa, com o desenvolvimento de um ambiente híbrido, com elementos de game e de appbook, que será retroalimentado com o feedback das crianças, professores, pais e especialistas, já que todas as ações do CPDCV, depois desse projeto, terão como meta qualificar sempre o GGF. Portanto, esse projeto marcou um novo percurso no grupo, que a partir de então se concentrará apenas nessa mídia. Assim, o GGF foi desenvolvido para tablete, para os sistemas operacionais IOS e Android, e encontra-se disponível gratuitamente para download nas Appstores.

\section{Processo de produção do Gamebook}

A segunda etapa concentrou-se nos aspectos de desenvolvimento, com momentos de validação da modelagem com os especialistas de neuropsicologia e, posteriormente, dos protótipos. Será descrito aqui apenas o processo de produção dos minigames.

Foram produzidos oito minigames, os quais tinham como objetivo principal potencializar as funções executivas de memória de trabalho, planejamento, flexibilidade cognitiva, categorização, controle inibitório e atenção seletiva.

É importante ressaltar que os minigames não estimulam apenas uma função cognitiva por vez, pois elas se estruturam e organizam de forma interdependente. Contudo, cada minigame tem o objetivo de priorizar uma determinada FE. Assim, quando a FE é memória de trabalho, a ênfase é a capacidade de reter uma informação e transformá-la ou integrá-la a outras informações para produzir outras informações; a flexibilidade cognitiva corresponde à capacidade de alterar o foco, considerando diferentes possibilidades e situações; atenção seletiva está associada à capacidade de selecionar o que é importante para uma determinada tarefa; o controle inibitório implica no controle do comportamento quando uma atividade não corresponde ao esperado, inibindo a atenção a outros estímulos que possam desviar o foco para a atividade desempenhada; o planejamento envolve a habilidade de criação e execução de um plano de ação (BARROS; HAZIN, 
2013; DIAS; SEABRA, 2013). Convém ressaltar que não existe uma padronização da nomenclatura dessas funções, consequentemente, é possível encontrar denominações diferentes para elas.

As funções executivas, portanto, ajudam e orientam a organizar e planejar as ações dos sujeitos no mundo em que vivem e são responsáveis por coordenar as funções cognitivas (BARROS; HAZIN, 2013).

Os minigames foram construídos para avaliar uma função executiva por vez, mas poderão avaliar mais de uma função ao mesmo tempo. Ainda que as funções executivas estejam sendo estimuladas em todo o ambiente do gamebook, os minigames atuam como espaço de observação, coleta e análise dos dados relativos à performance do jogador-leitor. ${ }^{3}$ Estes dados serão armazenados e podem ser acessados pelos profissionais que venham a utilizar esta ferramenta no contexto educacional e/ou clínico. Desta forma, é possível acessar informações sobre a evolução no desenvolvimento dessas funções, conforme o jogador-leitor interaja com a mídia.

Figura 1 - Desempenho

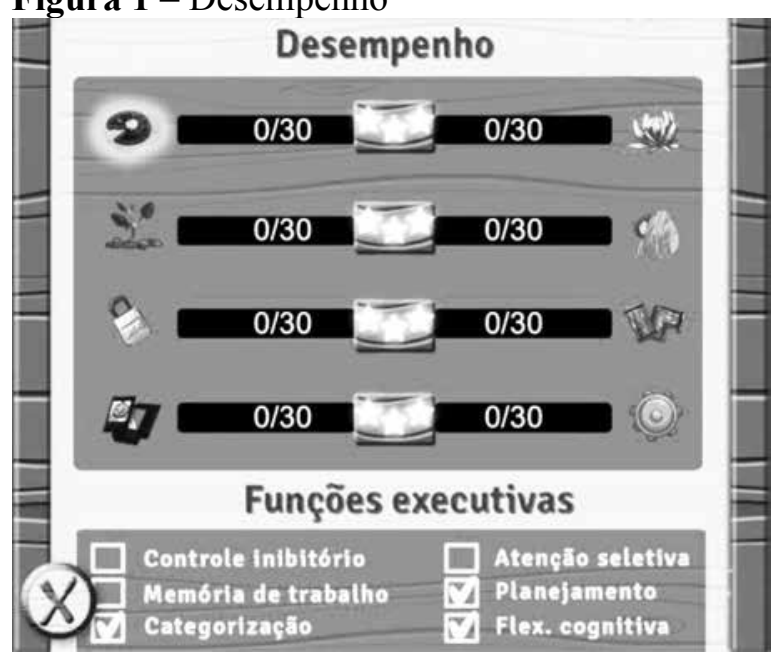

Fonte: Comunidades Virtuais (2016).

$\mathrm{Na}$ interface acima, o jogador-leitor, o professor, os pais e/ou o especialista podem identificar quais funções executivas são estimuladas em cada minigame, bastando apenas clicar no círculo próximo ao ícone do minigame. Por exemplo, no minigame da 3 O jogador leitor também pode ser compreendido como um interator - na perspectiva de Murray (2003). O interator é aquele que improvisa o caminho determinado pelo autor e pelas obras das novas mídias, a exemplo do Gamebook. vitória-régia, as FE estimuladas são categorização, atenção seletiva e planejamento. Esta interface é importante para que o próprio usuário direcione seu processo de estimulação.

Outra interface importante no gamebook refere-se à performance do jogador-leitor. À proporção que for interagindo com os minigames, ele vai puder acompanhar o desempenho das suas funções executivas, verificando quais as que precisam ser mais ou menos estimuladas.

Figura 2 - Performance das Funções executivas

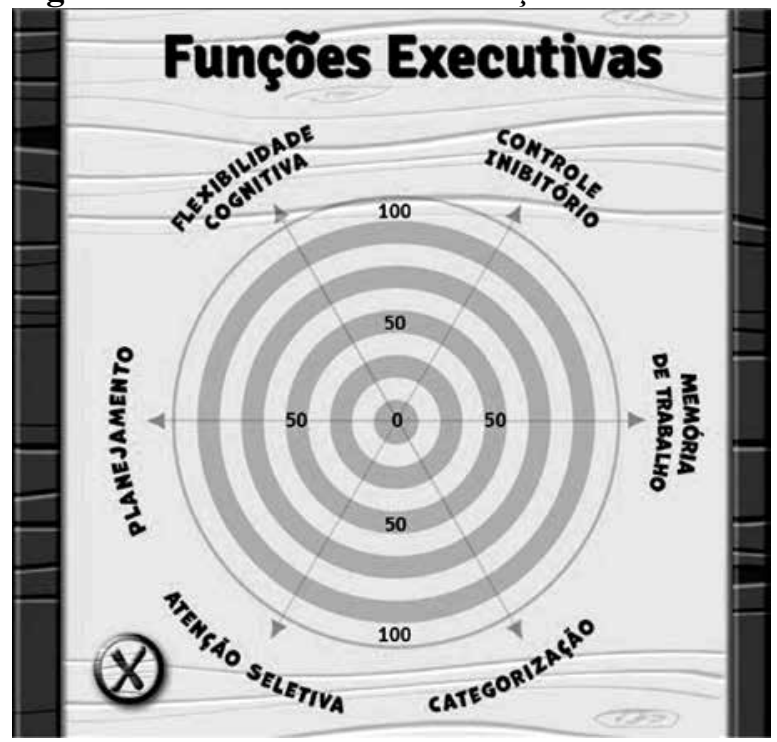

Fonte: Comunidades Virtuais (2016).

Os minigames ficam dispostos em diferentes momentos do fluxo da narrativa, podendo o jogador-leitor ter, em algumas situações, liberdade para escolher o momento de interação. Eles foram planejados para evoluir de um nível mais simples, no qual pode funcionar como um treino inicial, até etapas mais complexas, em que são exigidos melhores resultados na performance do jogador-leitor. Cada minigame possui 10 níveis de complexidade, sendo a passagem de níveis associada ao próprio desempenho do jogador-leitor.

\section{Descrição dos minigames e respectivas funções executivas avaliadas}

Minigame 1 - Vitória-Régia: no centro da tela, o jogador-leitor visualizará duas colunas com di- 
versas formas vazias, que simulam o formato de uma folha de vitória-régia, e nas laterais da tela, peças em movimento com o mesmo formato. $\mathrm{O}$ jogador-leitor é instruído a encaixar as peças em movimento nas peças de referência no centro da tela antes que elas afundem. A variabilidade de formatos das peças e a velocidade das peças em movimento vão variando conforme o nível de complexidade aumenta. O jogador-leitor poderá ganhar bônus pelo seu desempenho quanto mais rápido ele finalizar a tarefa.

O jogo finaliza caso o jogador-leitor consiga completar a tarefa no tempo estipulado ou o tempo finalize antes da tarefa ser finalizada. O jogador-leitor é estimulado a desenvolver prioritariamente a atenção seletiva, tendo em vista que é desafiado a selecionar o estímulo adequado em detrimento dos distratores. No entanto, ao mesmo tempo, necessita exercitar a habilidade de planejamento, visto que necessita cumprir a tarefa no tempo-limite, bem como monitorar as peças que estão afundando.

Outra função executiva exercitada é o controle inibitório, ao ter que inibir a ação de encaixar a peça em movimento na peça de referência não correspondente e assim perder pontuação. No contexto da narrativa, este minigame está associado ao momento em que a personagem principal Lyu necessita atravessar o rio em busca de seus pais. Ela precisa que o caminho das vitórias-régias esteja completo para atravessar o rio, de uma margem à outra, pisando nas folhas de vitória-régia.

Minigame 2 - Flor da Lua: o jogador-leitor visualizará um conjunto de caixas fechadas que possuem a flor da lua em seu conteúdo interno. No primeiro momento, essas flores são mostradas em determinadas caixas. No segundo momento, essas caixas são fechadas e o jogador deve clicar nas caixas correspondentes em que as flores estavam. O posicionamento das flores e das caixas vai variando de forma randômica ao avançar do jogo. Conforme os níveis de complexidade vão avançando, outros tipos de flores vão sendo incluídas para confundir o jogador, mas ele será sempre instruído a clicar apenas nas caixas que contenham a flor da lua.

O jogo finaliza quando o tempo acaba ou quando finaliza o número de caixas abertas. $\mathrm{O}$ jogador-leitor é estimulado a desenvolver a memória de trabalho ao ter que lembrar as caixas onde estavam as flores, podendo fazer uso de estratégias de memorização na tarefa. Ressalta-se que outras funções executivas, como controle inibitório, também estarão sendo desenvolvidas, principalmente com o avançar dos níveis do jogo, quando o jogador-leitor deverá inibir a ação de clicar na caixa que não contenha a flor da lua. No contexto da narrativa, este minigame apresenta-se como um desafio para que a personagem principal adentre a árvore sagrada Sumaúma, a casa dos guardiões da floresta.

Minigame 3 - Replantio: o jogador-leitor visualizará na parte superior da tela árvores de diferentes cores e na parte inferior espaços ocos para o plantio. Ele é instruído a preencher a sequência de espaços ocos com as árvores a partir do feedback fornecido por tentativa e erro. Cada vez que errar a sequência do plantio, deverá reiniciar o processo.

O jogador-leitor deverá recordar a sequência do plantio para avançar e solucionar a tarefa, que vai constantemente mudando, de forma randomizada. O jogo finaliza quando se completa a sequência correta dentro do tempo-limite ou caso o tempo finalize antes. O jogador é estimulado a desenvolver essencialmente a memória de trabalho, tendo em vista que necessita armazenar a sequência do plantio a partir do feedback fornecido pelo jogo. Porém, também é capaz de estimular a flexibilidade cognitiva ao ser exigido que modifique sua estratégia de resolução de problema com a mudança de feedback na sequência do plantio, conforme o jogo avança. No contexto da narrativa, este minigame também se apresenta como um desafio para que a personagem principal adentre a árvore sagrada Sumaúma.

Minigame 4 - Jaulas: o jogador-leitor irá visualizar na tela principal um conjunto de jaulas com animais presos. As jaulas apresentam um número variado de correntes, e quanto maior a quantidade, maior o nível de dificuldade da tarefa. Ele será orientado a quebrar as jaulas para libertar os animais. Com esse intuito, deverá escolher uma das jaulas e realizar algumas tarefas. No nível inicial, após clicar na jaula, ele visualizará a jaula trancada na parte superior da tela e uma barra horizontal com uma área verde em destaque, na parte inferior, e sobre ela um ponteiro que se move de um lado a outro da barra. 
O jogador-leitor é orientado a clicar sobre a zona verde assim que o ponteiro passar por cima desta área. A velocidade do ponteiro vai aumentando com o avançar do jogo, bem como o tamanho da zona verde vai diminuindo, desafiando o jogador-leitor a acertar o momento certo de clicar sobre a zona verde, conforme a passagem do ponteiro. Também é acrescentada uma zona vermelha simultaneamente à verde, e mais um ponteiro, porém ele continua a ser instruído a clicar na zona verde com o ponteiro inicial. Quanto mais jaulas quebradas, maior é a pontuação, e quanto mais difícil o nível, maior a recompensa.

O jogo é finalizado quando consegue quebrar as jaulas ou quando o tempo termina antes que tenha conseguido concluir a tarefa. Esse minigame avalia principalmente o controle inibitório, visto que o jogador-leitor deve inibir a ação de clicar na área ou botão errado, reduzindo o efeito de estímulos distratores e cumprindo com a regra do jogo. A atenção seletiva também é estimulada no momento em que o jogador-leitor é solicitado a direcionar a atenção para os botões ou cores solicitadas, em detrimento dos distratores. No contexto da narrativa, a personagem principal está sendo desafiada pelo lobisomem Luno a demonstrar força e habilidade, características fundamentais para ela se tornar uma guardiã da floresta.

Minigame 5 - Cartas: o jogador-leitor visualizará no centro da tela quatro cartas dispostas diametralmente e uma no centro. As quatro cartas alternam de posição num sistema rotatório e a carta do centro permanece fixa. Estas cartas possuem imagens que pertencem a classes de seres humanos, animais, lendas do folclore, objetos e plantas. Quando a carta do centro não pertencer àquela classe, o jogador-leitor deve clicar na carta e arrastá-la para a lixeira que aparece no canto inferior da tela. Quando pertencer à classe, deverá clicar e arrastar até a carta pertencente à sua respectiva classe. A velocidade de aparecimento das cartas vai aumentando gradativamente. Conforme o jogo for avançando, a complexidade da tarefa aumenta, pois as cartas dispostas diametralmente ficarão ocultas e o jogador-leitor será desafiado a recordar a posição da carta a ser relacionada com a carta do centro. $\mathrm{O}$ jogo finaliza quando o tempo-limite é atingido. Este minigame avalia prioritariamente a categorização, tendo em vista que se é estimulado a identificar elementos que apresentam características similares. O jogador-leitor também será capaz de desenvolver a memória de trabalho na etapa em que as cartas ficarem ocultas.

$\mathrm{Na}$ narrativa, esse minigame aparece no momento do desafio colocado pela sereia Iara à personagem Lyu. Para se tornar uma guardiã, ela precisa mostrar que conhece os elementos da floresta, e esta tarefa vai demonstrar essa habilidade.

Minigame 6 - Escondidos: o jogador-leitor visualizará a imagem da floresta ao fundo e a figura de um personagem do jogo surgirá em diferentes partes da tela. O jogador-leitor será orientado a clicar sobre a figura todas as vezes e em qualquer espaço que ela apareça. A figura se multiplicará sobre a tela exigindo agilidade e destreza do jogador-leitor. Com o avançar do jogo, aparecerão outros elementos clicáveis, que não os personagens, e ele será solicitado a não clicar sobre eles. O jogo termina quando o tempo finaliza.

Esse minigame estimula essencialmente a atenção seletiva, considerando que deverá direcionar o foco para os personagens clicáveis e colocar em segundo plano os distratores. No entanto, conforme o jogo avança, o controle inibitório também poderá ser potencializado, tendo em vista que deverá inibir a ação de clicar sobre os elementos não clicáveis. Flexibilidade cognitiva também poderá ser desenvolvida, pois o interator será exigido a mudar o curso da ação de acordo com novas exigências ambientais. No contexto da narrativa, este minigame também se apresenta como um desafio para que a personagem principal adentre a árvore sagrada Sumaúma.

Minigame 7 - Tubulações: o jogador-leitor visualizará na tela uma série de tubos desconectados e, ao final, a entrada para chegar na fábrica da Aragon. O interator será instruído a conectar os tubos, escolhendo as melhores peças, evitando áreas bloqueadas e formando o melhor caminho para adentrar a fábrica. O interator deverá clicar sobre os tubos para realizar o movimento de rotação e posicioná-los adequadamente na formação do caminho. O desafio encontra-se em realizar a tarefa com o menor número de cliques possíveis e seguindo o tempo cronometrado. O jogo finaliza quando completa-se a tarefa no tempo exigido ou o 
tempo se esgota antes que a tarefa seja completada. Este minigame avalia principalmente o planejamento, pois exige que o jogador-leitor estabeleça a melhor forma de alcançar o objetivo, considerando hierarquia nos passos e a utilização adequada dos tubos para alcançar a meta. Pode avaliar também o controle inibitório, considerando que deve inibir respostas inadequadas, como o excesso de cliques sobre os tubos, para não perder pontuação. $\mathrm{Na}$ narrativa do jogo, esse minigame ajudará Lyu a entrar na fábrica e salvar seus pais.

Minigame 8 - Fábrica: o jogador-leitor visualizará, na tela principal, o painel de segurança da fábrica, um sistema mecânico composto por uma malha de conexões e peças vermelhas e verdes que deverão mover-se por essa malha a partir dos cliques que serão dados pelo jogador-leitor no intuito de destravar esse sistema. O jogador-leitor será instruído a fazer uma combinação de peças pelo critério de cor, direcionando essas peças por meio desse sistema de malhas para que os pais de Lyu sejam libertados da fábrica. Para isso deve clicar na peça, por exemplo, de cor verde, observar as setas que indicam os caminhos que ela pode percorrer, escolher o caminho, ir clicando sobre ele até que as peças de mesma cor se encontrem. Um feedback é fornecido ao jogador-leitor indicando que fez a combinação exata. $\mathrm{O}$ desafio é promover a combi- nação de peças da mesma cor sem que as peças da outra cor se choquem.

O jogo termina quando o jogador completa todas as possibilidades de combinação de peças ou o tempo-limite finaliza. Esse minigame potencializa principalmente o planejamento, pois estimula o jogador-leitor a identicar a melhor forma de resolver o problema, antecipando possíveis choques entre peças de cores diferentes e demandando que o jogador-leitor hierarquize os passos para resolver esse problema no tempo-limite. Pode também desenvolver flexibilidade cognitiva, tendo em vista a necessidade de mudança de estratégia ao se deparar com possíveis choques entre as peças de cores diferentes. Na narrativa, esse minigame será o último desafio, exigindo que Lyu desative esse painel para libertar seus pais.

\section{A avaliação da mídia}

Esta etapa contou com a colaboração, mais uma vez, dos especialistas, os quais eram colaboradores do projeto e, nesta fase inicial, atuaram como avaliadores internos. Os especialistas foram escolhidos por terem experiência em Neuropsicologia, realizando avaliação, intervenção e/ou pesquisa na área. Uma breve descrição do currículo segue no Quadro 1.

Quadro 1 - Descrição dos currículos dos especialistas

\begin{tabular}{|c|l|}
\hline Especialista & Breve descrição do currículo \\
\hline A & $\begin{array}{l}\text { Psicóloga, mestre em Saúde Coletiva, experiência na clínica com crianças, } \\
\text { jovens, adultos e idosos e em pesquisa na área de Neuropsicologia do } \\
\text { Desenvolvimento. Docente da UNEB e da Faculdade Ruy Barbosa. }\end{array}$ \\
\hline B & $\begin{array}{l}\text { Psicólogo, mestre em Psicologia, experiência em pesquisa na área de Avaliação } \\
\text { Psicológica e Neuropsicológica, Neurociências cognitiva, comportamental e do } \\
\text { desenvolvimento. Integrante do Grupo de Pesquisa Neuropsicologia Clínica e } \\
\text { Cognitiva (NEUROCLIC). Docente da UNEB, da Escola Bahiana de Medicina e } \\
\text { Saúde Pública e do Centro Universitário Jorge Amado. }\end{array}$ \\
\hline C & $\begin{array}{l}\text { Psicóloga, especialista em Neuropsicologia, mestre em Medicina e Saúde, } \\
\text { experiência em atendimento neuropsicológico com crianças, adultos e idosos. } \\
\text { Docente da Faculdade Maurício de Nassau. }\end{array}$ \\
\hline
\end{tabular}

Fonte: Elaborado pelos autores deste artigo.

Os especialistas foram solicitados a avaliar quais funções neuropsicológicas estavam con- templadas em cada minigame e discriminar um percentual para cada função identificada. $\mathrm{O}$ 
minigame 8 não pôde ser avaliado, pois ainda estava em processo de finalização da produção.
O parecer de cada especialista está disposto no Gráfico 4.

Gráfico 4 - Avaliação das funções executivas contempladas em cada minigame por especialista

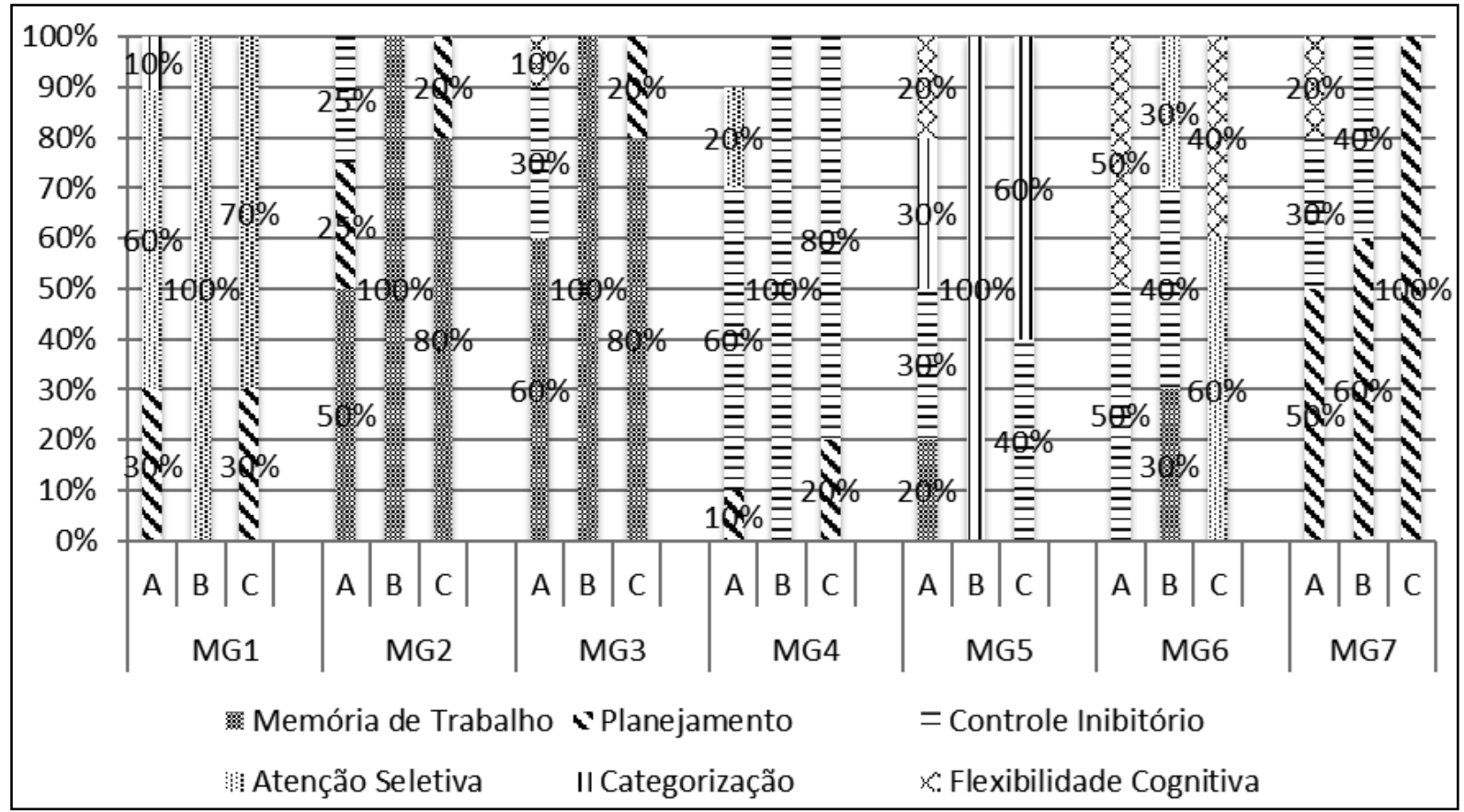

Fonte: Elaborado pelos autores deste artigo.

No Gráfico 4 pode-se perceber que houve uma alta concordância no parecer dos especialistas, com exceção do minigame 6 . De acordo com a avaliação, verificou-se que o minigame 1 está avaliando majoritariamente a atenção seletiva; os minigames 2 e 3, a memória de trabalho; o minigame 4, o controle inibitório; o minigame 6 , a categorização; e o minigame 7, o planejamento. A discordância ocorreu no minigame 6 , em que o especialista A apontou para avaliação concomitante de controle inibitório e flexibilidade cognitiva, o especialista $\mathrm{B}$ apontou para controle inibitório apenas e o especialista $\mathrm{C}$ para a atenção seletiva. Ressalta-se que os minigames podem avaliar mais de uma função ao mesmo tempo, ainda que o minigame 6 tenha sido planejado para potencializar principalmente a atenção seletiva. Observou-se também uma concordância entre o parecer dos especialistas e o que foi pretendido no processo de produção dos minigames. Estes resultados são parte do processo de avaliação interna, devendo ainda ser ratificados por uma avaliação externa. ${ }^{4}$

4 Nos meses de outubro e novembro de 2015 foram iniciados novos
A investigação que vem sendo desenvolvida com a mediação do gamebook aponta um diferencial em relação às pesquisas existentes, pois se propõe a estimular as funções executivas de crianças na faixa etária de 8 a 12 anos.

\section{Conclusão}

Os dados parciais, apresentados anteriormente, já sinalizam as contribuições que o Gamebook pode trazer para a comunidade escolar, clínica e investigadores, tendo em vista a ausência de ambientes, como esse, que possam estimular as funções executivas. O processo de pré-produção, produção e avaliação evidenciaram o potencial desse produto no contexto pedagógico e clínico com crianças que possam apresentar problemas no desenvolvimento das funções executivas, especialmente TDAH. Na pré-produção, buscou-se observar os principais elementos que constituiriam

processos de avaliação do gamebook com novos especialistas, pesquisadores da área de neuropediatria e neuropsicologia. Estes resultados serão publicados em outro artigo. 
essa mídia, considerando o contexto de interação e preferências do nosso futuro público-alvo. O estudo com similares possibilitou completar as informações fornecidas pelas crianças e desenvolver uma mídia que pudesse fazer parte do universo delas. A colaboração multirreferencial também foi fundamental em todo o processo de produção. Nesta abordagem, contempla-se diferentes olhares para a mesma realidade, sem excluir a contradição, a multiplicidade e a heterogeneidade que permeiam as relações. Os saberes são considerados incompletos e constantemente ressignificados (ALVES, 2013).

Os minigames buscaram adotar mecânicas específicas para estimular as funções executivas e fornecer informações aos usuários, como professores, pais e profissionais de saúde. A partir do processo de avaliação da mídia, os avaliadores internos constataram que as funções de atenção seletiva, planejamento, categorização, flexibilidade cognitiva, memória de trabalho e controle inibitório estavam adequadamente contempladas nos minigames, parte fundamental do gamebook para observar a performance do jogador-leitor durante o processo de potencialização de tais funções.

$O$ projeto encontra-se na fase de investigação junto as crianças com diagnóstico de TDAH, que após uma avaliação neuropsicológica irão interagir com o Gamebook a fim de investigar o nível de estimulação deste ambiente para as funções executivas destes sujeitos. Ressaltamos ainda que as pesquisas vinculadas a este projeto configuram a tendência que vem sendo denominada pelo grupo de pesquisadores e desenvolvedores do Akili (AKILI, 2015) de Electronic Medicine, isto é, a mediação de jogos digitais no tratamento de transtornos como TDAH, autismo, dentre outros, nos quais o jogador/paciente interage de qualquer lugar e é acompanhado pelos médicos e pesquisadores. Tal perspectiva vai muito além do uso da medicalização.

Assim, o artigo aqui proposto apresenta os resultados da primeira fase da investigação, que com base na avaliação dos especialistas conclui que os ambientes interativos, como o gamebook, podem se constituir em lócus de aprendizagem e estimulação das FE.

\section{REFERÊNCIAS}

AKILI INTERACTIVE. Scientific approach. 2015. Disponível em: $<$ http://www.akiliinteractive.com/>. Acesso em: 03 mar. 2016.

ALVES, L. R. G. Games e educação: desvendando o labirinto da pesquisa. Revista da FAEEBA, Salvador, v. 22, p. 177-186, 2013.

AMERICAN PSYCHIATRIC ASSOCIATION (APA). Manual Diagnóstico e Estatístico de Transtornos Mentais - DSM-V. Tradução Maria Inês Correia Nascimento. Porto Alegre: Artmed, 2015.

ANDERSON, P. Assessment and development of executive function (EF) during childhood. Child Neuropsychology, v. 8, n. 2, p. 71-82, 2002.

.Video game may help treat ADHD. Medscape, 29 Oct. 2015. Disponível em: $<$ http://www.medscape.com/ viewarticle/853420>. Acesso em: 02 mar. 2016.

ANGUERA, J. A. et al. Video game training enhances cognitive control in older adults. Nature, v. 501, p. 97-101, set. 2013. Disponível em: <http://www.nature.com/nature/journal/v501/n7465/full/nature12486.html $>$. Acesso em: 02 mar. 2016.

ASSOCIAÇÃO BRASILEIRA DO DÉFICIT DE ATENÇÃO (ABDA). O que é TDAH. 2016. Disponível em: $<$ http://www.tdah.org.br/br/sobre-tdah/o-que-e-o-tdah.html>. Acesso em: 02 mar. 2016.

BADDEley, A.; ANDERSON, M. C.; EYSENCK, M. W. Memória. Porto Alegre: Artmed, 2010.

BARROS, P.; HAZIN, I. Avaliação das funções executivas na infância: revisão dos conceitos e instrumentos. Revista Psicologia em pesquisa, Juiz de Fora, MG, v. 7, n. 1, p. 13-22, 2013. Disponível em: <http://www.ufjf.br/ psicologiaempesquisa/files/2013/08/02-v7n1.pdf>. Acesso em: 31 maio 2014.

BOYLE, J; BOYLE, Elizabeth. Towards an understanding of the relationship between executive functions and 
learning outcomes from serious computer games. In: PROCEEDINGS OF THE GAMES AND LEARNING ALLIANCE CONFERENCE (GALA 2013), 2014, Heildeberg. Annals... Heidelberg, 2014. Lecture Notes in Computer Science, p. 187-199.

BURNHAM, T. F. Complexidade, multirreferencialidade, subjetividade: três referências polêmicas para a compreensão do currículo escolar. Em aberto, Brasília, DF, ano 12, n. 58, p. 3-13, abr./jun. 1993.

BUSINESS WIRE. Pilot study results demonstrate akili's mobile digital intervention improved attention and working memory in pediatric Attention Deficit Hyperactivity Disorder. 2015. Disponível em: <http://www. businesswire.com/news/home/20151028005996/en/Pilot-Study-Results-Demonstrate-Akili\%E2\%80\%99s-Mobile-Digital>. Acesso em: 12 fev. 2016.

CAPOVILLA, A. G. S.; ASSEF, E. C. dos S.; COZZA, H. F. P. Avaliação neuropsicológica das funções executivas e relação com desatenção e hiperatividade. Avaliação Psicológica, Porto Alegre, v. 6, n. 1, p. 51-60, jun. 2007.

COMUNIDADES VIRTUAIS. Gamebook Guardiões da Floresta. 2016. Disponível em: $<$ http://comunidadesvirtuais.pro.br/guardioes-gamebook/>. Acesso em: 02 mar. 2016.

Guardiões da Floresta. 2013. Disponível em: $<$ http://comunidadesvirtuais.pro.br/guardioesdafloresta/ $>$. Acesso em: 02 mar. 2016.

CORTÁZAR, Julio. O jogo de amarelinha. São Paulo: Martins Fontes, 2005.

DIAMOND, A. Executive functions. Annual Review of Psychology, v. 64, n. 1, p. 135-168, 2013

DIAS, N. M.; SEABRA, A. G. Piafex: programa de intervenção em autorregulação e funções executivas. São Paulo: Memnon, 2013.

FUNDAÇÃO TELEFONICA. Livro e Game. 2011. Disponível em: <http://www.livroegame.com.br/>. Acesso em: 10 mar. 2016.

GIL, A. C. Como elaborar projetos de pesquisa. 5. ed. São Paulo: Atlas, 2008.

GOLDBERG, Elkhonon. O cérebro executivo: lobos frontais e mente civilizada. Rio de Janeiro: Imago, 2002.

INNOVATION EXCELLENCE. Innovate digital medicine: Akili video game for HDAD intervention. 2015. Disponível em: < http://www.innovationexcellence.com/blog/2015/11/02/innovative-digital-medicine-akili-video-game-for-adhd-intervention/>. Acesso em: 10 mar. 2016.

INSTITUTO CLARO. Game Minecraft é adotado para fins educacionais. 2013. Disponível em: <https://www. institutoclaro.org.br/blog/game-minecraft-e-adotado-para-fins-educacionais/>. Acesso em: 01 set. 2015.

JOY STREET. OJE. Disponível em: <http://www.joystreet.com.br/oje.html>. Acesso em: 02 mar. 2016.

JUNQUEIRA, Daniel. Um jogo para smartphones e tablets promete ajudar no tratamento do déficit de atenção. Gizmodo Brasil, 2016. Disponível em: <http://gizmodo.uol.com.br/um-jogo-para-smartphones-e-tablets-promete-ajudar-no-tratamento-do-deficit-de-atencao/>. Acesso em: 12 fev. 2016.

MALlOY-DINIZ, L. F. et al. (Org.) Avaliação Neuropsicológica. Porto Alegre: Artmed, 2010.

MINECRAFT ganha site que irá reunir dicas para usar o jogo na educação. O Globo, Rio de Janeiro, 02 jul. 2015. Disponível em: $<$ http://g1.globo.com/tecnologia/games/noticia/2015/07/minecraft-ganha-site-que-ira-reunir-dicas-para-usar-o-jogo-na-educacao.html>. Acesso em: 01 set. 2015.

MURRAY, J. H. Hamlet no Holodeck - o futuro da narrativa no ciberespaço. São Paulo: UNESP/Itaú Cultural, 2003.

PAI, Adite. Study: mobile gaming intervention may help children with ADHD. Mobi Health News, 28 Oct. 2015. Disponível em: <http://mobihealthnews.com/48045/study-mobile-gaming-intervention-may-help-children-with-adhd>. Acesso em: 12 fev. 2016.

RETALIS, Symeon. et al. Empowering children with ADHD learning disabilities with the Kinems Kinect Learning Games. PROCEEDINGS OF THE EUROPEAN CONFERENCE ON GAMES BASED LEARNING, 2014, Berlin. Annals... Berlin, 2014. Vol. 2, p. 469.

SANTAELLA, Lucia. Navegar no ciberespaço - o perfil cognitivo do leitor imersivo. São Paulo: Paulus, 2004. 
YAMAMOTO, Karina. Professor de SP usa Minecraft para estimular criatividade e cooperação. UOL Educação, São Paulo, 12 mar. 2015. Disponível em: <http://educacao.uol.com.br/noticias/2015/03/12/professor-de-sp-usa-minecraft-para-estimular-criatividade-e-cooperacao.htm>. Acesso em: 01 set. 2015.

Recebido em: 05.03.2016

Aprovado em: 19.06 .2016 